\title{
ФОРМИРОВАНИЕ ПРОИЗВОДСТВЕННОЙ БАЗЫ ТАНКОВОЙ ПРОМЫШЛЕННОСТИ НА УРАЛЕ В КОНЦЕ 1941 - НАЧАЛЕ 1942 Г. ${ }^{1}$
}

\section{FORMATION OF THE PRODUCTION BASE OF THE TANK INDUSTRY IN THE URALS IN LATE 1941 - EARLY 1942}

\section{Zapariy N. Melnikov}

Summary: One of the most interesting events in the history of the Great Patriotic War was the evacuation of personnel and equipment of prewar maintained tank-building and cooperation industries located in the center and in the west of the USSR, with their subsequent reorganization in the eastern regions. This work aims to summarize the regional features of the formation of the production base of the PCTI (People's Commissariat of the Tank Industry of the USSR) in the Urals, clarifies role of region as the leading production and technological center of the leading Soviet tank building, in 1941-1942.

Keywords: military economy, tank industry, evacuation, Ural, People's Commissariat of the tank industry, the Great Patriotic War.
Запарий Василий Владимирович К.и.н., н.С., Институт истории и археологии Уральского отделения РАН (Екатеринбург)

pantera.zap@gmail.com

Мельников Никита Николаевич

К.и.н., С.н.с., Институт истории и археологии Уральского отделения РАН (Екатеринбург) meln2011kit@gmail.com

Аннотация: Одним из наиболее интересных явлений в истории Великой 0течественной войны является эвакуация расположенных в центре и на западе СССР кадров и оборудования довоенных танкостроительных и смежных с ним производств с последующим восстановлением их в восточных регионах. Данная работа ставит целью обобщить региональные особенности формирования производственной базы НКТП (Наркомата танковой промышленности Союза (СР) на Урале, поскольку роль региона как ведущего производственного и технологического центра всего советского танкостроения в 1941-1942 гг. возросла многократно.

Ключевые слова: военная экономика, танковая промышленность, эвакуация, Урал, Наркомат танковой промышленности, Великая Отечественная война.

(Свердловск, Н. Тагил, Челябинск). Производственная база танковой промышленности, созданная в экстремальных условиях начального периода войны, сумела поддержать резко упавший общесоюзный объем выпуска бронетехники и обеспечить действующую армию танками в сложный период зимы 1941 - весны 1942 гг., однако столкнулась с кризисом надёжности и неспособностью быстро наращивать валовый выпуск. Для преодоления кризисных явлений партийно-государственное руководство СССР использовало имевшийся у него до войны опыт командного администрирования в сочетании с максимально возможным внедрением высокопроизводительных промышленных технологий фордистского типа $[2,6,7]$.

Решение о формировании заводов-дублеров по выпуску перспективных образцов бронетехники, принятой на вооружение в конце 1930-х гг., было принято советским руководством весной 1940 г. ЧТЗ (Челябинский тракторный завод) предназначается для создания на Урале новой базы производства тяжёлых танков «КВ», тяжелых танков, опиравшиеся на крупнейшие промышленные города Свердловской и Челябинской областей

На основе соединения эвакуированных мощностей крупнейших довоенных танкостроительных предприятий и промышленного потенциала созданных в 1930-е гг. индустриальных гигантов, к началу 1942 г. на Урале сформировалось два крупнейших территориальнопроизводственных комплекса по выпуску средних и 
разработанных на Кировском заводе в Ленинграде. Одновременно с развёртыванием серийного выпуска Т-34 на головном заводе № 183 в Харькове СТ3 (Сталинградский тракторный завод) получает приказ начать подготовку к крупносерийному производству харьковской машины, начиная с 1941 г. Это решение было обосновано внутри советского военно-политического руководства в рамках неформальной дискуссии 1930-х гг. о путях дальнейшего развития военной промышленности и механизмах ее мобилизации. Изучался опыт развития экономики ведущих индустриальных держав мира, таких как США, Германия и Великобритания. Руководители советской индустрии отмечали отсутствие у США специально организованной военной промышленности, полагая, что, опираясь на свою высокоразвитую гражданскую промышленность, США имеют возможность быстро наладить выпуск любой военной продукции в кратчайшие сроки. Американские промышленные технологии рубежа 1920-1930-х гг. были признаны в СССР, наиболее подходящими для заимствования, т.к. были ориентированы на массовое производство. По этой причине в СССР родилась концепция своеобразной «ассимиляции» традиционно существующих специализированных военных заводов в систему, вновь создаваемых на американский манер (и по американским же технологиям) гигантами машиностроения [1].

Так, начало крупномасштабному танковому производству в СССР 1930-х гг. было положено путем создания обособленного объединения (Спецмаштрест) ряда машиностроительных предприятий, имевших специализированное промышленное оборудование и рабочие кадры универсальной квалификации. Реализовать планы «ассимиляции» гражданской и военной отраслей к началу Великой Отечественной войны все же не удалось, поскольку технологическое оснащение новых машиностроительных заводов, опыт и квалификация рабочих и технических кадров оказались недостаточным для быстрого и качественного освоения танкового производства [1, с. 113].

К лету 1941 г. создаваемые в Поволжье и на Урале центры танковой промышленности не смогли выйти на установленные объемы выпуска, будучи еще зависимы от поставок ключевых комплектующих, таких как двигатели, радиооборудование, вооружение. Внутриведомственное взаимодействие головных заводов-разработчиков и заводов-реципиентов было развито слабо. Разработанные к концу 1930-х гг. прототипы танкового мотора, получившие после завершения испытаний индекс B-2, несмотря на свои выдающиеся технические показатели, оказались чрезвычайно неудобны для массового производства в условиях ускоренной индустриализации СССР. Освоение иных, более простых узлов и элементов боевых машин (ходовая часть, элементы трансмиссии) для гражданских предприятий оказалось не менее проблематичным. Основные производители танковой брони до войны - Ижорский и Мариупольский заводы - располагались далеко от новых центров танкостроения. Прямое привнесение технологий, пригодных для «кадровых» военных заводов, на почву только что созданных гражданских автотракторных предприятий в условиях СССР рубежа 1930-1940-х гг. оказалось неосуществимо. Более того, заводы, непосредственно участвовавшие в производстве танков и их комплектующих (моторов, трансмиссии, бронекорпусов и вооружения), продолжали находиться в ведении различных отраслевых наркоматов. В силу сочетания этих факторов, причине выйти на заданные плановые показатели по новым танкам ЧТЗ и СТ3 к июню 1941 г. не сумели.

Начало Великой Отечественной войны ознаменовалось ускорением развития замещающих производств танков Т-34 и «КВ» в тыловых районах страны. Так, в период июля-августа 1941 г. проводятся мероприятия по повышению степени локализации танкового производства «КВ» на Урале с целью быстрого наращивания темпов суточного выпуска. С 3 по 23 июля 1941 г. из Ленинграда в Свердловск вместе со своими кадрами и станочным парком на площадку недавно запущенного УТЗ (Уральского турбинного завода) был перебазирован дизельный цех Кировского завода. На новом месте предполагалось организовать полный цикл сборки танковых дизель-моторов В-2 (и топливной аппаратуры к ним), необходимых для выполнения резко возрастающей программы сдачи тяжелых танков ЧТЗ; в начале декабря 1941 г. новый УТЗ был разделен на собственно турбинный завод и дизельный завод № 76 НКТП [8, л. 92-94]. В июле 1941 г. также начались работы по организации производства бронекорпусов тяжелого танка «КВ» на Уралмашзаводе. Эти меры должны были сократить время подвоза ведущих комплектующих (двигатели и бронекорпуса), ранее поставлявшихся на Урал из западных районов СССР, которые теперь оказались под ударами противника. Был осуществлен демонтаж и переброска уникальных бронепрокатных станов с Ижорского и Мариупольского заводов и отправка их на восток.

К началу осени 1941 г. оперативная обстановка на фронтах ухудшилась настолько, что СССР оказался под угрозой полной потери основных производственных мощностей танковой промышленности. Сначала Ленинград оказался отрезан от основных сил Красной армии и как промышленный центр оказался выключен из общего экономического пространства, в начале сентября 1941 г. была нарушена работа южного центр танкостроения, опиравшегося на Харьков и Мариуполь. Началась эвакуация кадров и оборудования танковых и смежных производств из Ленинграда, Мариуполя и Харькова, что сопровождалось разрушением довоенной системы 
взаимной кооперации. Для координации действий по эвакуации и восстановления заводов производителей бронетехники в сентябре 1941 г. создается Наркомат танковой промышленности СССР (НКТП), который возглавляет В.А. Малышев. На государственном уровне ход эвакуации контролировал Совет по эвакуации под началом Н.М. Шверника.

Оборудование и кадры основных танковых заводов Ленинграда (Кировский, № 174, Ижорский завод) в несколько этапов вывозились на восток. Первоначально кадры и оборудование Кировского и Ижорского завода должны были разместиться на базе машиностроительных предприятий Челябинской и Свердловской областей, сформировав территориально-производственный комплекс под называнием Уральский комбинат тяжелых танков «УКТТ» [3, с. 53]. Его ядром должен был стать ЧТЗ, уже к лету 1941 г., производивший танки «КВ» небольшими сериями. На ЧТЗ перемещались кадры и оборудование Кировского завода, рабочие, служащие, инженеры, а станочный парк Ижорского завода был разделен между Уралмашем (который с трудом осваивал сборку бронекорпусов «КВ») и вновь создаваемым в Челябинске бронекорпусным заводом № 200. Двигатели для тяжелых «КВ» должен был поставлять дизель-моторный участок Уральского турбинного завода.

После начала немецкого наступления на Донбассе в сентябре 1941 г. эвакуация танкового и дизель-моторного производства южной группы стала неизбежной. Чтобы свести к минимуму эффект от прекращения производства Т-34 и дизель-моторов В-2, была принята стратегия эвакуации этих предприятий «по частям» (когда одна часть кадров и оборудования завода вывозится, а другая продолжает работать). Однако в условиях быстро ухудшавшейся оперативной обстановки начала октября 1941 г. эти расчеты не оправдались. Хотя ключевые инженерно-технические работники и служащие «Харьковского куста» заводов НКТП, непосредственно вовлеченные в танковое производство, были спешно вывезены на восток, подавляющую часть рабочих-сборщиков, имевших опыт серийной сборки Т-34, вывезти не удалось, как и почти все энергетическое, крановое и металлургическое оборудование [3, с. 55-56].

Отсутствие подходящих резервов для размещения эвакуированного из Харькова такового и дизельного производства как единого комплекса привело к решению их разделить. В новых условиях ХПЗ № 183 им. Коминтерна был отправлен в Н. Тагил на площадку Уралвагонзавода, а двигательное производство завода № 75 было встроено в структуру нового Кировского завода на базе ЧТЗ. Таким образом, эвакуация завода № 183 на Урал в октябре-ноябре 1941 г. привела к быстрому сворачиванию реализации идеи «УКТТ», открыв дорогу для формирования двух территориально-производственных комплексов по выпуску средних и тяжелых танков. Особенностью функционирования этих комплексов стало тесное административное, технико-технологическое взаимодействие и кооперация входящих в них заводов. Такая тенденция определила последующую унификацию технологических процессов и стандартов массового производства во всей танковой промышленности региона.

По прибытию в Н. Тагил на Уралвагонзавод ХПЗ № 183 до конца декабря 1941 г. собрал несколько партий танков из имевшегося задела комплектующих и корпусов, после чего встал вопрос о полной реорганизации технологических процессов. Имевшийся к осени 1941 г. кадровый потенциал, возможности металлургического оборудования и станочного парка Уральского вагонного завода (УВЗ) не обеспечивали возможности в кратчайший срок воссоздать в Н. Тагиле довоенный уклад работы, характерный для танковых цехов ХПЗ № 183 в Харькове. Сказалось отсутствие (или потеря в ходе эвакуации) дефицитных металлорежущих станков, термических печей, штамповочного и прессового оборудования, а также свободных помещений в цехах. Требовалось срочно начать крупносерийную сборку корпусов для Т-34 непосредственно на Урале [9, л. 2].

Директор завода Е.Ю. Максарев, понимал, что в условиях постоянно растущей программы выпуска Т-34 необходимо провести крупномасштабную реконструкцию ключевых цехов с перспективой перехода к поточноконвейерной сборке. Этому обстоятельству способствовала и эвакуация на Урал основных отраслевых научноисследовательских институтов, включенных в структуру НКТП. В частности, в Н. Тагил на УВЗ был перебазирован Институт Электросварки (ИЭС) АН УССР во главе с академиком Е.О. Патоном. Сотрудники ЦНИИ-48 (Центральный броневой институт НКТП) были командированы на крупнейшие металлургические заводы Урало-Кузбасса и формирующиеся уральские танковые и корпусные заводы НКТП с целью обеспечить в кратчайшие сроки перестройку всего комплекса технологических процессов в сфере разработки, производства и обработки танковой брони [4, с. 72-76].

Под руководством ведущих инженеров и технических работников этих институтов на рубеже 1941-1942 гг. на Урале началась полномасштабная перестройка эвакуированных танковых заводов к условиям господства малоквалифицированной рабочей силы и недостатка специализированного промышленного оборудования. Оставшихся в оккупированном Харькове и ушедших на фронт специалистов пришлось заменять в основном местными кадрами, не имеющими опыта танкового производства, либо трудмобилизованными из 
других отраслей хозяйства. Для работы в условиях потери высококвалифицированных сварщиков в Н. Тагиле были отлажены вывезенные из Харькова автосварочные установки довоенного образца, сконструированы новые; создавалась специальная высокопроизводительная оснастка для кантовки и сварки корпусов Т-34. Все эти технико-технологические усовершенствования интегрировались в главное новшество того времени - бронекорпусной конвейер.

Процесс трансформации технологического процесса на заводе № 183 в Н. Тагиле по объективным причинам затянулся и привел к срыву государственного плана выпуска крайне необходимых фронту танков Т-34. На фоне похожих трудностей у СТ3 и горьковского завода № 112, а также крайне напряженной обстановки на фронте, в феврале 1942 г., постановлением ГКО, директор завода № 183 Е.Ю. Максарев был снят с поста. На его место был назначен зам. наркома танковой промышленности И.М. Зальцман, ранее успешно (с точки зрения советского руководства) осуществивший восстановление Кировского завода в Челябинске. Используя свои административные возможности и получив от ГКО разрешение на любые чрезвычайные действия, И.М. Зальцман в течение месяца сумел добиться запуска сборки Т-34 на основе поточно-конвейерной технологии. При этом Е.Ю. Максарев был оставлен в качестве главного инженера и фактически вел непосредственную работу на местах. Таким образом, И.М. Зальцман сумел укрепить свой авторитет в глазах ГКО и лично И.В. Сталина, как «человек, который умеет делать танки», при этом не разрушив карьеру Е.Ю. Максарева, который вскоре был восстановлен в должности директора завода № 183 [5, с. 18-25].

Эвакуация на Урал московской группы заводов НКТП, расположенных в центральном промышленном районе, проходила в течение ноября 1941 г. Кадры и оборудование группа заводов, занятых сборкой легких танков на основе автомобильных агрегатов (КИМ, завод № 37, Подольский завод им. Орджоникидзе) первоначально планировалось эвакуировать в Ташкент на завод сельскохозяйственных машин. После того как руководство НКТП трезво оценило возможности экономики этого региона, было решено перенаправить эшелоны в Свердловск один из крупнейших индустриальных центров страны, оставшихся в строю. Но и здесь компактно разметить эти мощности не получилось, поскольку наиболее удобные для этого заводские территории были уже перегружены (например, УзТМ или Уралтурбозавод).

Прибывшие в город эшелоны должны были сформировать новый, единый завод № 37, разделённый территориально между тремя локациями. Так, на территории вагоноремонтного завода им. Воеводина расположился Подольский завод, на площадке свердловского завода
«Металлист», а также автогаража Облотдела связи - части бывших московских заводов КИМ и № 37. На новом месте дирекция завода № 37 изначально попыталась воссоздать прежний принцип организации производства. Несмотря на внедрение принципов замкнутого цикла обработки деталей и создание поточных линий, общий недостаток площадей и неизбежные в ходе эвакуации потери оборудования привели к параличу работы заготовительных цехов и похоронили надежды дирекции завода и аппарата НКТП на быструю отладку бронекорпусного участка методом конвейерной сборки $[10$, л. 4-8].

Еще более критической оказалась зависимость нового завода от поставок таких важных комплектующих, как двигатели, вооружение, элементы подвески и ходовой части. Все они поставлялись кооператорами, находившимися в сотнях километров от завода, в условиях перегруженных транспортных коммуникаций; сами кооператоры систематически срывали план поставок, т.к. зачастую не могли решить даже собственные насущные проблемы на производстве (особенно Кировский завод в Челябинске и ГАЗ). Несмотря на меры административного регулирования, принятые ГКО и НКТП в 1942 г., регулярные поставки заводу № 37 организовать так и не удалось. Уже весной 1942 г. кадры и оборудование завода № 37 вливаются в структуру УзТМ на правах филиала. Дополнительным соображением в пользу отказа от завода лёгких танков в Свердловске стало понимание невысокой боевой ценности легких танков в военных условиях начала 1942 г., а также наличие такого крупного производителя легкой бронетехники, как ГАЗ.

Таким образом, на рубеже 1941-1942 гг. произошло формирование производственной базы уральского танкостроения за счет соединения эвакуированных из западных районов страны кадров и оборудования с мощностями местных машиностроительных предприятий. Несмотря на большие успехи, достигнутые уральской экономикой в годы предвоенных пятилеток, сложившийся здесь народно-хозяйственный комплекс оказался в целом не подготовлен к приему такого количества эвакуированных заводов. Почти одномоментное (в течение всего трех месяцев) шоковое увеличение нагрузки на слаборазвитую социальную инфраструктуру, энергетические и транспортные сети, рассчитанные на потребности местного населения, значительно осложнили период восстановления. Несмотря на то, что по формальным признакам восстановление эвакуированных танковых заводов на Урале произошло быстро и к январю 1942 г. заводы № 37 и № 183 выдали первые танки на новых местах, а Кировский завод в Челябинске сумел увеличить свою производительность, вся отрасль встала перед необходимостью коренных управленческих и технологических трансформаций. 
Потеря квалифицированных кадров, неполная или некомплектная доставка имущества эвакуированных заводов и полный развал выстроенной до войны системы кооперации наиболее чувствительно сказались в области заготовительных операций, негативно повлияв на качество выпускаемой танковой брони, ее закалки, сварки бронекорпусов и механической обработки ключевых элементов боевых машин. Производство танковой брони (ее варка, прокатка, литье и термообработка), ранее осуществлявшееся специализированными военными заводами, преимущественно Ижорским и Мариупольским, в новых условиях пришлось передать гражданским металлургическим гигантам Урала и Кузбасса. До войны КМК, ММК и НТМЗ выпускали преимущественно гражданский сортамент изделий.

Огромную роль в процессе трансформации гражданской металлургии Урала на службу военным целям сыграли эвакуированные в регион специалисты отраслевых научно-исследовательских институтов НКТП. Им удалось приспособить технологический процесс броневого производства к условиям отсутствия специального металлургического (особенно прокатного и термического) оборудования ценой заметного понижения качества выпускаемой брони средней твердости. Эта броня, ставшая основой бронезащиты самого массового танка Красной армии - Т-34 была чрезвычайно чувствительна к неукоснительному соблюдению технологического процесса ее изготовления на всех этапах - от варки до закалки, правки и последующего отпуска. Сюда же можно отнести чувствительность к точности регламента сварочных работ и газовой резки. В связи с падением уровней квалификации рабочей силы и оснащенности производства дефекты корпусов Т-34 стали обыденным явлением в 1942-1944 гг. Броня средней твердости, используемая для сборки корпусов и башен тяжелых танков, оказалась менее чувствительна к подобным изъянам.

Дизель-моторное производство также сильно пострадало от потери квалифицированных специалистов, поскольку выпуск В-2 и особенно топливной аппаратуры к нему требовал обработки деталей по первому классу точности [11, л. 4-5]. Моторные производства (завод № 76 и дизельный цех Кировского завода), развернутые на Урале к концу 1941 г., остро нуждались в полуфабрикатах, не имели собственной заготовительной базы по основным категориям литых и штампованных деталей. Основной поставщик этих изделий - Уралмаш не справлялся с необходимым объемом поставок и сам переживал нелегкий период превращения в один из крупнейших танковых заводов страны.

Таким образом, развитие производственной базы уральского танкостроения за период с начала Великой
Отечественной войны и до начала 1942 г. происходило в режиме экстренного реагирования на молниеносные изменения оперативной обстановки на фронте и резкого ухудшения военно-политической ситуации на советско-германском фронте. Создаваемые с началом боевых действий стратегические планы эвакуации и развёртывания военной промышленности приходилось постоянно корректировать. Изначальные планы по эвакуации Кировского завода на Урал и создание здесь «Уральского комбината тяжелых танков» (УКТТ) можно рассматривать как вполне реальные, тем более что еще с начала 1941 г. ЧТЗ начал осваивать серийный выпуск тяжелых «КВ». Соединение наиболее квалифицированных кадров Кировского завода с имеющимся потенциалом ЧТЗ делало возможным формирование достаточно устойчивого территориально-производственного комплекса по выпуску тяжелых танков, каким изначально и задумывался УКТТ. Последующее продвижение немецких войск на Донбасс и в центральный промышленный район в сентябре-ноябре 1941 г. привело к экстренной эвакуации на Урал также производства средних танков Т-34 и моторов к ним (г. Харьков), а также группы Московских заводов-изготовителей легких танков. В итоге, медленно формирующаяся еще с середины 1940 г. производственная база танковой промышленности Урала пережила одномоментный взрывной количественный рост. При этом качественные улучшения в столь кроткий срок по объективным причинам были недостижимы, поэтому в течение 1942 г. в отрасли развернулась коренная трансформация базовых технологических процессов.

Период этой трансформации совпал с масштабным кризисом качества, особенно сильно ударившим по программе выпуска Т-34 - основного танка Красной армии. Именно в силу заложенных в его конструкцию прогрессивных с точки зрения инженерной науки того времени технических решений: мощного дизель-мотора и сварного корпуса из противоснарядной брони высокой твердости. Но в условиях эвакуации и резкого падения технического уровня танкового производства эти технические решения превратились в факторы, снижавшие надежность Т-34. Такое положение вещей частично компенсировалось оптимизацией конструкции, внедрением высокопроизводительных методов обработки и автоматизации наиболее сложных операций. Это выразилось в повсеместном отказе от малопроизводительной (в условиях потери массы квалифицированных кадров и дефицитного промышленного оборудования) универсальной технологии, характерной для довоенных «кадровых» танковых заводов. Ей на смену пришла максимально специализированная, упрощенная автотракторная, поточно-конвейерная технология сборки, позволявшая наладить производство в условиях доминирования кадров средней и низкой квалификации. 


\section{ЛИТЕРАТУРА}

1. Бугров К.Д., Запарий В.В. Танкостроение в контексте военно-хозяйственной стратегии СССР 1930-х гг. // Вестник Томского государственного университета. 2019. № 448. С. 108-118.

2. Ермолов А.Ю. Танковая промышленность СССР в 1940-е годы: от мобилизации на нужды войны к реконверсии // Вопросы истории естествознания и техники. 2015. Т. 36. № 2. С. 300-305.

3. Запарий В.В. Танковая промышленность на Урале в 1940-е годы. Екатеринбург: УмЦ-УпИ, 2015. 218 с.

4. Запарий Вас.В., Запарий В.В. Отраслевая наука танкопрома в годы Великой Отечественной войны: вклад в решение задач инженерно-технической оптимизации броневого производства в 1941-1945 гг. Ч. 1 // Черные металлы. 2020. № 10. С. 72-76.

5. Запарий Вас.В. Роль Государственного Комитета Обороны (ГКО) в государственном управлении танковой промышленностью СССР и Урала в 1941-1945 гг. // Вестник Южно-Уральского Государственного университета. Серия: Социально-гуманитарные науки. 2017. Т. 17. № 1. С. 18-25.

6. Меерович М.Г. Фордизм и постфордизм. Альберт Кан и Эрнст Май: (ША и Германия в борьбе за советскую индустриализацию // Постфордизм: концепции, институты, практики. М.: Политическая энциклопедия, 2015. С. 171-222.

7. Мельников Н.Н. Модернизация танковой промышленности СССР в условиях Великой Отечественной войны. Екатеринбург: Сократ, 2017. 416 с.

8. Российский государственный архив социально-политической истории. Ф. 644. Оп. 1. Д. 1.

9. Государственный архив Свердловской области. Ф. Р-262. Оп. 1. Д. 24.

10. Объединенный государственный архив Челябинской области. Ф. Р-792. Оп. 3. Д. 8.

11. Российский государственный архив экономики. Ф. 8752. Оп. 4. Д. 360.

(c Запарий Василий Владимирович (pantera.zap@gmail.com), Мельников Никита Николаевич (meln2011 kit@gmail.com).

Журнал «Современная наука: актуальные проблемы теории и практики»

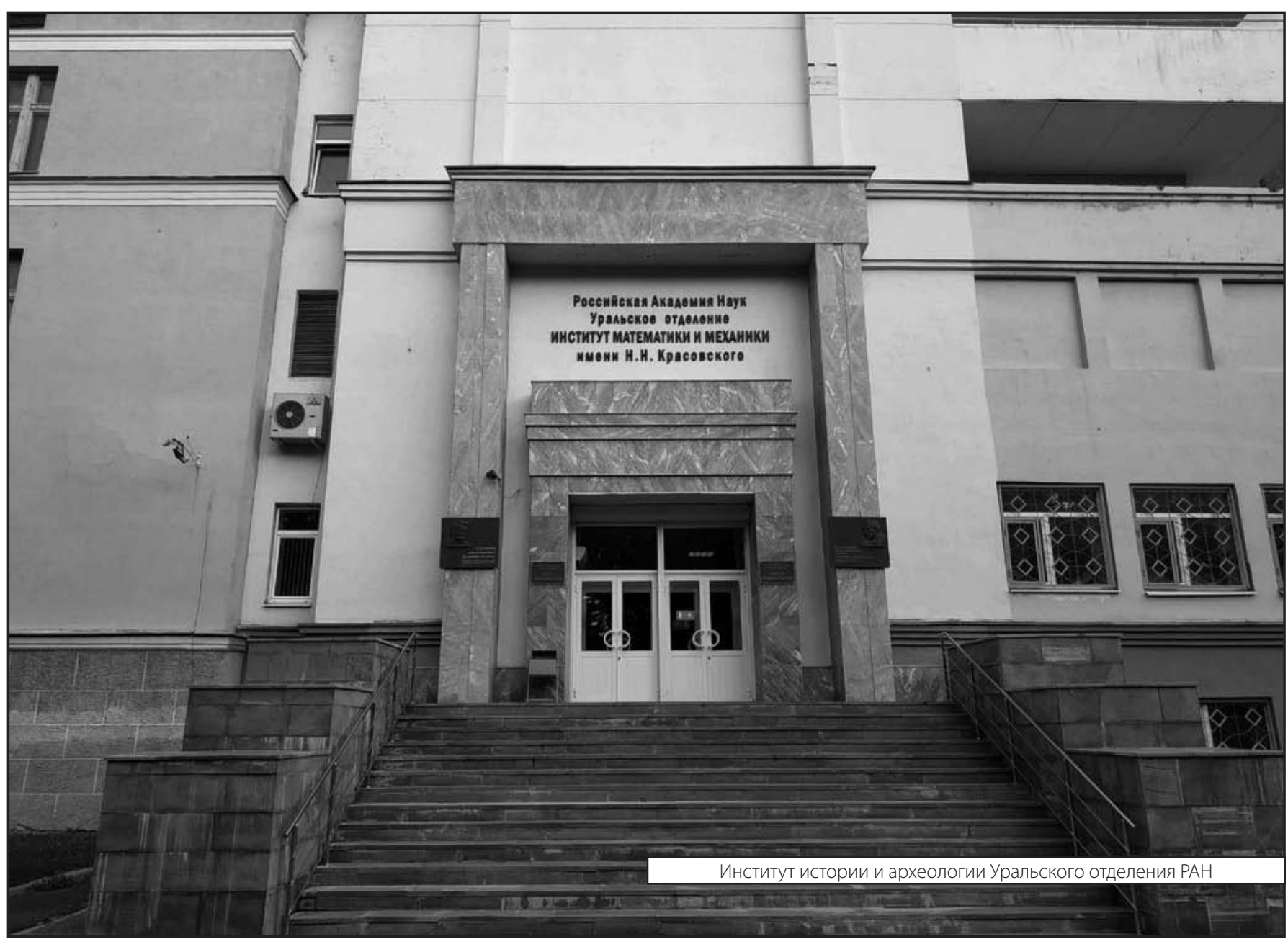

